\title{
Games e Gamificação: uma alternativa aos modelos de EaD
}

\section{Games and gamification: an alternative for distance education models}

\author{
Eliane Schlemmer \\ Universidade do Vale do Rio dos Sinos (Brasil)
}

\section{Resumo}

O problema que dá origem a esse artigo consiste em investigar como os games e a gamificação podem contribuir para a criação de novos desenhos na Educação a Distância (EaD). O objetivo foi compreender a contribuição dos games e da gamificação, pensados a partir do movimento "Games for Change", na perspectiva da configuração de Espaços de Convivência Híbridos, Multimodais e Pervasivos para a aprendizagem, numa aproximação entre a formação inicial e a educação básica. A pesquisa é exploratória e qualitativa, inspirada no método cartográfico de pesquisa-intervenção. Faz uso da observação participante, diário de bordo e registros em texto, áudio, fotografia e vídeo digitais. Os dados são interpretados a partir do referencial teórico. Como conclusão, os resultados apontam que os Games e a Gamificação possibilitaram o desenvolvimento de situações de ensino e de aprendizagem que se configuraram enquanto Espaço de Convivência Híbrido, Multimodal e Pervasivo, num processo de co-criação, a partir da leitura critíca do cotidiano da educação básica, onde foram identificadas problemáticas, as quais os games e gamificação poderiam contribuir para mudanças. Houve maior engajamento dos sujeitos da aprendizagem e ressignificação da experiência vivenciada na formação inicial para o ensino fundamental, a partir da leitura critica do cotidiano da escola. A discussão surge sobre a necessidade de reconfiguração das práticas pedagógicas e currículos, bem como a forma de organizá-lo no tempo e no espaço, a partir de problemáticas cotidianas, possibilitando a construção de percursos de aprendizagens, de forma a contribuir para uma educação emancipatória e cidadã.

Palavras-chave: educação a distância; ensino superior; educação básica; games e gamificação; hibridismo, multimodalidade e pervasividade.

\begin{abstract}
This article presents research about how the games and gamification can contribute to the creation of new drawings in distance education. The goal was to understand the contribution of games and gamification, thought from "Games for Change" movement in view of Hybrids, Multimodal and Pervasive Coexistence Spaces configuration for learning, an approach between initial training and basic education. The research is exploratory and qualitative, inspired by the cartographic method of intervention research. It uses participant observation, the logbook and text records, audio, photo and digital video. The data are interpreted from the theoretical framework. In conclusion, the results show that the games and gamification
\end{abstract}


enabled the development of teaching and learning situations that are configured as Hybrid, Multimodal and Pervasive Coexistence Space, a process of co-creation, from the critical reading of the everyday basic education, which sought to identify problems and how games and gamification could contribute to changes in the school. There was a greater engagement of the subjects of learning and reframing of lived experience in the initial training for primary education, from the critical reading of the school routine. The discussion arises about the need for reconfiguration of the teaching and curriculum practices, and how to organize them in time and space, starting from everyday problems, enabling the construction of learning pathways to contribute to an emancipatory education and citizen.

Keywords: digital education; distance education; higher education; basic education; games and gamification; hybridity, multimodality and pervasiveness.

A motivação para desenvolver a pesquisa surge: 1) da inquietação com o cotidiano da docência no Ensino Superior, principalmente vinculado a modalidade EaD; 2) da percepção do distanciamento entre as práticas pedagógicas desenvolvidas no ensino superior e a forma como os sujeitos aprendem, considerando os meios com os quais interagem; na relação com as práticas pedagógicas desenvolvidas na educação básica e a forma como os sujeitos aprendem, considerando os meios com os quais interagem e; 3) da necessidade de investigar o potencial dos games e da gamificação, num contexto de hibridismo, multimodalidade e ubiquidade, considerando as proposições do Bring Your On Device (BYOD) e do Flipped Classrom, como possibilitadores de experiências de conhecimento, que propiciem articulação efetiva entre a formação inicial e a prática pedagógica desenvolvida no Educação Básica. O desejo foi de que os sujeitos se sentissem instigados, curiosos e engajados no aprender, e que isso pudesse acontecer de uma forma divertida. Assim, identifica-se o problema: Como os games e a gamificação podem contribuir para a criação de novos desenhos na $\mathrm{EaD}$ que sejam significativos para os sujeitos do ponto de vista da aprendizagem?

Segundo Schlemmer (2014), a gamificação na educação consiste basicamente em utilizar a forma de pensar dos games, os estilos e as estratégias de games, bem como os elementos presentes no design de games, tais como mecânicas e dinâmicas (M\&D), em contextos não game, como meio para engajar os sujeitos na invenção e resolução de problemas (Ziechermann; Linder, 2010; Zichermann; Cunningham, 2011; Kapp, 2012; Fardo, 2013), em diferentes áreas e níveis educacionais (Domínguez et al., 2013).

A gamificação se ocupa então, de analisar os elementos que estão presentes no design de games e o tornam divertido, adaptando-os para situações que, normalmente, não são consideradas games, criando, desse modo, uma camada de game em uma situação, processo ou produto, no lugar de ser, na origem, um game. O conceito, embora criado em 2002, pelo britânico Nick Pelling, se amplia em 2008 com o crescimento da indústria de games e se dissemina, a partir de 2010, pela ampla utilização em diversos contextos. 
Vinculada à gamificação, está a perspectiva explicitada, por exemplo, por movimentos como o Games for Change, cujo objetivo consiste na utilização de games para o desenvolvimento social. Segundo McGonigal (2011) as pessoas preferem jogos de cooperação, elas querem trabalhar com seus amigos para atingir um objetivo comum, ou seja, estar juntos. De acordo com a autora, se os jogadores estão dispostos a realizar desafios que envolvem obstáculos, muitas vezes desnecessários, os jogos têm a capacidade de mobilizar, então, podem ser utilizados como instrumento para a transformação social. No caso dessa pesquisa essa transformação está vinculada ao cotidiano das instituições educacionais (ensino superior e educação básica).

A gamificação se propõe ainda, a empoderar os sujeitos e pode ser potencializada quando associada a tecnologias móveis e sem fio (TMSF), mídias sociais, web ubíqua, sistemas de geolocalização, realidade misturada (RM) e realidade aumentada (RA), o que possibilita falar em hibridismo, multimodalidade e ubiquidade, conceitos que serão explicitados posteriormente. A seguir apresenta-se o contexto no qual esse problema se insere.

A seguir, para o título das seções do artigo, bem como para a sua estrutura, são utilizados elementos do framework para gamificação (um dos resultados da pesquisa).

\section{COMPREENSÃO DO CONTEXTO}

Segundo Schlemmer \& Backes (2015) nos encontramos num cenário conectado e paradoxal - estar em qualquer lugar sem sair de casa, fronteiras fluidas, bordas permeáveis, lugares e presenças plurais. Assim, a cada dia nos tornamos mais íntimos das tecnologias digitais, pensamos "com" e "a partir" dessas tecnologias, construímos mundos virtuais nos quais também vivemos e convivemos. É justamente nesse viver, que vamos constituindo nosso conviver em distintos espaços presenciais físicos e online, permeados por diferentes tecnologias analógicas e digitais, que integram novos espaços para o conhecer.

Essa forma de conviver de determinado grupo evidencia um agir próprio, cria rituais que representam as emoções, estabelece valores comuns, normas para a própria convivência, construindo uma cultura, o que nos permite, por exemplo, nos referir a uma cultura digital ou a uma cultura gamer. Entretanto, na dinâmica do conviver entre diferentes grupos, criam-se territórios, lugares, de forma que os próprios espaços acabam por desenvolver uma cultura própria, o que nos permite, por exemplo, referir a cultura da escola, a cultura da formação de professores, a cultura da educação.

Maturana e Yáñez (2009, p. 216) afirmam que "a cultura não predetermina o viver que se viverá, mas quem cresce nela a incorpora, e sua corporalidade [corporificação] se transforma de modo que, a menos que ante uma disjuntiva ele ou ela reflexione sobre o que faz, escolhe sem escolher viver, o que o viver a cultura implica”. Assim, a manutenção da cultura existente, a transformação, o desenvolvimento e/ou a 
recriação está relacionada ao grau de consciência dos seres humanos em relação a si e ao outro, no sistema social ao qual pertencem.

Dessa forma, contextos vão se delineando e se modificando, a partir do imbricamento entre diferentes culturas, tanto no que se refere a grupos de seres humanos, quanto a espaços sociais, o que nos permite falar em cutura dos sujeitos e cultura do ambiente.

\section{Cultura dos sujeitos}

Com o objetivo de estabelecer diferenciações entre os sujeitos que nasceram num mundo digital, em relação aos nascidos num mundo pré-digital, alguns estudiosos e pesquisadores têm utilizado diferentes denominações (Schlemmer, 2016). Essas diferenciações e denominações são abordadas por alguns como uma questão geracional e por outros como uma questão cultural. No entanto, para além da classificação e da tipificação de comportamentos e hábitos de diferentes gerações e/ou cultura, ao observarmos algumas crianças e jovens que, em diferentes épocas, vem se desenvolvendo cada vez mais em interação com tecnologias - analógicas e digitais - é possível perceber mudanças profundas nos modos de viver e conviver. Elas desenvolveram uma forma de pensar e organizar o pensamento a partir de meios não só analógicos, mas também digitais, e essa combinação (construída nessa coexistência), tem possibilitado um nível de ação e de interação muitas vezes extremamente dinâmico e instantâneo. Em função dessa forma de agregação, em rede, fluída, a relação desses sujeitos com sistemas hierarquizados nem sempre é tranquila.

Considerando o exposto acima, em outro artigo Schlemmer (2016) afirma que adjetivações atribuídas tanto às gerações quanto à cultura evidenciam, muitas vezes, um pensamento binário, visões dicotômicas, percepções polarizadas, se considerarmos que os espaços são híbridos, multimodais, pervasivos e ubíquos, nos quais coexistem diferentes tecnologias, modalidades e culturas. Estamos falando de uma sociedade intercultural e multicultural que se desenvolve e, ao mesmo tempo, impulsiona o desenvolvimento de diferentes tecnologias analógicas e digitais, de forma que, simultaneamente, podemos estar interagindo num espaço analógico presencial físico e num espaço digital virtual - online; com objetos tanto analógicos, quanto digitais e desses combinados. É nesses novos espaços que os sujeitos, em movimentos nômades agem e interagem, tecendo relações num imbricamento com outros atores humanos e não humanos, em diferentes tempos, na construção de um mundo de significados. Isso nos leva a pensar que uma nova compreensão de cultura e de sociedade possa estar emergindo, numa perspectiva de coexistência, de respeito mútuo, de solidariedade interna, de reconhecimento do outro como legítimo outro na interação. Portanto, não se trata de encontrar uma nova denominação para essa geração, cultura e/ou sociedade que está emergindo, a fim de não cairmos novamente 
nas armadilhas que um pensamento binário e reducionista nos coloca, mas sim, de pensarmos a partir da complexidade que isso engendra.

Então, interessa-nos compreender o que essas mudanças podem significar para os diferentes sujeitos que compõe o contexto educacional. Como se dá a interação entre os docentes e os estudantes? Como se dá o engajamento nos processos de ensino e de aprendizagem? O que acontece na relação entre os docentes e estudantes, que se encontram em um espaço híbrido? De que forma essa interação contribui para a própria formação docente. E por fim, o que pode ser feito - nas escolas, nas organizações, incluindo as universidades, para potenciar a inventividade nas práticas pedagógicas?

No âmbito deste artigo os estudantes são professores em formação inicial em Pedagogia.

\section{Cultura do ambiente}

A cultura do ambiente, nesse caso, se refere à cultura do ensino superior, ao qual está vinculada a Atividade Acadêmica Ensino e Aprendizagem no Mundo Digital AA-EAMD, mais especificamente no âmbito do Curso de Graduação em Pedagogia. A AA-EAMD é ofertada semestralmente na modalidade $\mathrm{EaD}$, com uma carga horária de 6oh, distribuída em 20 encontros semanais, sendo 6 presenciais físicos. Para os encontros presenciais físicos faz uso de sala de aula - Laboratório de Informática e, para os encontros online, faz uso do Ambiente Virtual de Aprendizagem Moodle. Segue os processos institucionais no que se refere às questões de registro e avaliação, sendo essa última composta por dois momentos: Grau A e Grau B e, caso o estudante não atinja a nota mínima de 6,0 em um dos dois Graus, pode recuperar no Grau C. Conforme exigência da legislação brasileira, as avaliações são obrigatoriamente, desenvolvidas na modalidade presencia física. Nesse ambiente estão os docentes, que se constituem por meio de rotinas, convenções e costumes estáticos e monopolíticos, de um sistema com pouca flexibilidade. Diante disto, os aspectos culturais do ensino superior, condicionam e mediam, mas não determinam a ação do educador, que pela reflexão e autonomia na prática pedagógica, influencia a qualidade do processo educativo.

É nesse contexto que o educador pode, por meio de sua prática pedagógica, propiciar a configuração de espaços de convivência. Para Maturana e Varela (2002), a configuração dos espaços de convivência ocorre no fluxo de interações entre os seres humanos e entre os seres humanos e o meio, o que possibilita a transformação dos seres humanos e do meio, entrelaçados pelas emoções, percepções, representações, perturbações e compensação das perturbações. Entretanto, como o ambiente no qual os seres humanos vivem e convivem na atualidade, não é somente de natureza física, mas também de natureza digital, esse conceito é ampliado para espaços de convivência híbridos, multimodais e pervasivos. 
A Educação formal seja no âmbito da Educação Superior ou da Educação Básica, quando configurada como um espaço de convivência híbrido, multimodal e pervasivo, de cruzamento cultural, pode representar um espaço de promoção da autonomia, de construção da identidade e de crítica reflexiva para a emancipação cidadã.

A partir da identificação e compreensão do problema e do contexto, é possível definir o escopo da gamificação a ser desenvolvida, conforme a seguir.

\section{DEFINIÇÃO DO ESCOPO}

Faz parte da definição do escopo da gamificação a ser criada: os objetivos; as áreas do conhecimento envolvidas; as temáticas abordadas; as competências e habilidades a serem desenvolvidas, bem como conceitos relacionados; as ações, tipos de ações e input que podem ser potencializados. Assim, no que se refere a gamificação da AAEAMD temos:

\section{O que queremos alcançar com a AA-EAMD?}

A AA-EAMD (campo empírico) tem por objetivo criar espaços de aprendizagem e de emancipação digital, capazes de propiciar o desenvolvimento de postura teóricometodológica e conhecimento tecnológico, que favoreçam a integração de diferentes tecnologias digitais - TD na construção do conhecimento. Busca a reflexão sobre o uso dessas tecnologias para o desenvolvimento humano e social, no âmbito da educação infantil, anos iniciais e educação de jovens e adultos.

Considerando o objetivo da AA, acima referido, na relação com o problema e o contexto apresentados anteriormente, o objetivo da pesquisa, que envolve a gamificação da AA, consistiu em compreender a contribuição dos games e da gamificação, pensados a partir do movimento "Games for Change", na perspectiva da configuração de Espaços de Convivência Híbridos, Multimodais e Pervasivos, para a construção de práticas pedagógicas que possibilitem novos desenhos em educação, capazes de engajar os sujeitos na aprendizagem, num movimento de aproximação entre a formação inicial e a educação básica.

\section{Que áreas do conhecimento que serão envolvidas?}

A área do conhecimento a que se refere esse proceso de gamificação, inicialmente, é a educação, mais especificamente a educação digital. Entretanto, a partir da leitura do cotidiano das escolas, realizada pelas estudantes, outras áreas do conhecimento foram envolvidas, conforme necessidade do game ou processo gamificado desenvolvido por elas, nas escolas. 


\section{Quais as temáticas/temas a serem abordados?}

Foram as seguintes as temáticas abordadas: Características da Sociedade Industrial e da Sociedade em Rede; Influências e mudanças ocasionadas pelo uso das TD no mundo contemporâneo; Pressupostos epistemológicos, paradigmas educacionais e práticas pedagógicas; Utilização das TD no processo educacional; Modalidades educacionais; Games, Gamificação, BYOD, Flipped Classroom, Hibridismo, Multimodalidade, pervasividade e ubiquidade.

\section{Que competências/habilidades poderão ser desenvolvidas e que conceitos estão a elas relacionados?}

As competências e habilidades a serem desenvolvidas, bem como os conceitos a elas relacionados, envolveram: Utilizar as TD na educação numa visão crítica e humanística; Decidir quanto à escolha e uso das TD na prática pedagógica, identificando os pressupostos epistemológicos implícitos no desenvolvimento dos projetos e softwares; Reconhecer o paradigma educacional que norteia uma prática pedagógica com o uso dos TD; Criar um ambiente de aprendizagem desafiador capaz de promover o desenvolvimento da autonomia, a interação e a cooperação num processo de construção do conhecimento, favorecido pela pesquisa na busca de inovação educacional; Estabelecer relações entre a teoria, a vivência enquanto aluno e a prática pedagógica; Buscar e selecionar informações objetivando a construção de novos conhecimentos; Articular diferentes conhecimentos; Integrar vários softwares e mídias na realização de projetos de aprendizagem; Interagir e cooperar com os colegas; Criar e animar comunidades virtuais.

\section{Que ações, tipos de ações e input serão potencializadas?}

A gamificação da AA-EAMD iniciou com uma narrativa, que instigava os sujeitos a realizar uma análise do cotidiano das escolas, a fim de identificar problemas para os quais os games e a gamificação poderiam contribuir, transformando a realidade. Dessa forma, as ações foram de acompanhamento dos diferentes percursos de aprendizagem, desenvolvidos pelos sujeitos nos Clãs, tendo como suporte a atenção cartográfica, utilizando-se de TMSF, AVA Moodle, Evernote, Facebook, Ferramentas do Google, incluindo Google Hangout, geolocalização e marcadores digitais em QRCode, RA, RM, entre outros, capazes de promover a experiência da cartografia. Essa abordagem tem como inspiração o método cartográfico de pesquisaintervenção, inicialmente, proposto por Kastrup (2007), adaptado enquanto prática pedagógica intervencionista, associada a metodologia de projetos de aprendizagem e a perspectiva dos games e da gamificação. Apesar do método proposto por Kastrup estar orientado para a prática da pesquisa em ciências humanas, no 
Grupo de Pesquisa Educação Digital - GPe-dU UNISINOS/CNPq investigamos a potência desse método para acompanhar processos de aprendizagem em contextos de hibridismo, multimodalidade e pervasividade, bem como a possibilidade de apropriação do método por professores e estudantes em seus próprios percursos de aprendizagem. É nesse sentido, que a experiência que está sendo apresentada se desenvolveu, contemplando a formação inicial dos professores em Pedagogia e a prática pedagógica desenvolvida por eles com estudantes na educação básica, o que envolveu diferentes espaços da escola e da cidade.

É importante dizer que a proposta não consiste numa mera transposição do método, mas sim, em experimentar os movimentos da cartografia, enquanto prática pedagógica intervencionista e gamificada, na vinculação com os conceitos de Flipped Classroom e BYOD, na perspectiva da construção de espaço de convivência híbridos, multimodais e pervasivos. Nesse caso, a metáfora das pistas e do rastreio serviu de inspiração para concebermos a composição de trilhas, bem como para a própria progressão na gamificação. Rastreio (varreduras do campo), toque (aciona o processo de seleção), pouso (parada - zoom) e reconhecimento atento (percepção do contexto global das missões) foram consideradas achievements, ao mesmo tempo em que podem ser entendidas como skills (habilidades) para a própria jogabilidade e sociabilidade.

A metodologia contemplou ainda seminários com a participação de especialistas, em áreas específicas do conhecimento, de acordo com a temática abordada, missões e o desenvolvimento de projetos nos Clãs.

Os inputs foram acontecendo a partir da necessidade que foi surgindo em cada game ou proceso gamificado que estava sendo desenvolvido, como "resposta" a uma problemática identificada no cotidiano das escolas.

\section{A EXPERIÊNCIA}

Analisando o contexto, o desejo foi de que os sujeitos, ao vivenciar a experiência, se sentissem instigados, curiosos, provocados a identificar no cotidiano das escolas situações problemas na qual os games ou procesos gamificados pudessem contribuir, transformando as práticas. Dessa forma, a expectativa foi a de que houvesse um maior engajamento dos sujeitos da aprendizagem e que isso pudesse acontecer de uma forma divertida. Compreendido o problema e o contexto, e, definido o escopo inicial, foi realizado um diálogo com os estudantes da AA-EAMD, a fim de melhor conhecêlos, bem como identificar suas necessidades e expectativas. Após esse momento, foi apresentado o objetivo da atividade e colocado em discussão. Concluidas essas etapas é que se começou a pensar nos tipos de elementos presentes nos games (M\&D), que poderiam auxiliar na construção da gamificação a fim de garantir que o sujeito se sentisse da forma desejada e que permitisse atingir os objetivos pretendidos. 


\section{MECÂNICAS \& DINÂMICAS (fundamentação teórica e metodologia, desenvolvimento da experiência)}

\section{Sobre Games e Gamificação - games for change}

Após ter identificado e compreendido o problema e o contexto, definido o escopo, bem como a forma como se deseja que os jogadores se sintam, faz-se necessário pensar nas mecânicas e dinâmicas que podem possibilitar que os sujeitos se sintam daquela forma e atinjam os objetivos pretendidos. A mecânica é a lógica do jogo, é o conjunto de regras, procedimentos e programações. A dinâmica são as interações propiciadas pelas mecânicas do jogo.

Os elementos mais comuns encontrados na mecânica dos games envolvem um sistema de pontuação, quadro de ranking, recompensa, premiação, conhecidos como (points, badges, and leaderboards - PBL). Entretanto, a gamificação não se reduz a perspectiva do PBL, considerada uma mecânica simples, fácil de ser implementada, escalável e de baixo custo, o que contribui para que se dissemine rapidamente. Embora estejam presentes no design de muitos games para motivar comportamento e direcionar os sujeitos para determinadas ações, o PBL não torna algo chato em algo mais emocionante, pois falha principalmente no que se refere ao engajamento dos sujeitos. Muitos autores, tais como Chou (2015), refere que os pontos, as medalhas e o quadro de ranking são importantes como bônus, dependendo do contexto. Segundo ele, existe uma diferença entre motivação extrínseca (onde você está envolvido por causa de um objetivo ou recompensa) e a motivação intrínseca (onde a atividade em si é divertida e emocionante, com ou sem uma recompensa).

A perspectiva do PBL é denominada por Chou (2015) como a "casca de uma experiência de jogo", é uma visão reducionista da gamificação e, muitas vezes, presta um desserviço à área, uma vez que pessoas com conhecimento superficial sobre a metodologia e a filosofia da gamificação, acabam por acreditar que gamificar algo consiste basicamente na criação de um sistema de pontuação, distribuição de medalhas e quadro de ranking, reduzindo a gamificação a um modismo, algo superficial e de baixo poder de inovação. A presença desses elementos podem ser indicador de uma lógica indutiva e reativa, que geralmente está presente numa abordagem empirista de educação, dessa forma, persuasiva, promovendo verdades únicas e estimulando a competição, pois, o outro é sempre, ou melhor, ou pior que você, nunca o diferente com quem se pode aprender.

Numa outra abordagem, elementos distintos podem estar presentes na mecânica, tais como: trilhas, desafios, enigmas e missões mais complexas e problematizadoras que envolvem a relação com diversas variáveis e uma postura dedutiva e exploratória na busca de pistas, na realização de descobertas, no desenvolvimento de estratégias, na organização em clãs que agrupam jogadores com características diversas e gera um empoderamento em grupo, para construção colaborativa e cooperativa - o que do ponto de vista pedagógico nos leva à perspectiva epistemológica interacionista- 
construtivista-sistêmica (inspirados, por exemplo, por elementos presentes nos Massively Multiplayer Online Role Play Game - MMORPG). É importante que essas mecânicas sejam coerentes com as competências e habilidades que pretendemos desenvolver, ou seja, a ação do jogador no jogo deve refletir a proposta educacional.

Para o contexto da AA-EAMD, um dos elementos definidos foi o de que a gamificação se daria em um contexto híbrido, multimodal e pervasivo, cuja mecânica teve início com uma narrativa instigadora. De acordo com Schlemmer, Chagas e Shuster (2015), a narrativa envolveu a criação de Clãs organizados a partir da análise do cotidiano das escolas e já com a parceria da escola para o seu desenvolvimento, ou seja, com o desenvolvimento do projeto uma mudança entrou em curso na escola (Educação Básica). No que se refere às regras, a gamificação foi composta por trilhas, que representavam os diferentes percursos trilhados por cada Clã. O trabalho nos Clãs envolveu a realização de missões, com objetivos e achievements, as quais foram inspiradas nas pistas do método cartográfico de pesquisa-intervenção (Passos, Kastrup, Escóssia, 2009), mais especificamente, no que tange as quatro variedades da atenção cartográfica, adaptadas enquanto metodologia para o desenvolvimento, acompanhamento e avaliação dos percursos de aprendizagem, realizados pelos sujeitos, conforme a seguir:

Tabela 1. Missão, Objetivos e Achievements

\begin{tabular}{|c|c|c|}
\hline Missão & Objetivos & Achievements \\
\hline $\begin{array}{l}\text { Rastreio } \\
\text { (varreduras do } \\
\text { campo) }\end{array}$ & $\begin{array}{l}\text { - conseguir um parceiro, encontrar } \\
\text { as pistas, } \\
\text { - criar a narrativa da gamificação, } \\
\text { - convencer o parceiro da } \\
\text { importância da causa (conseguir } \\
\text { o comprometimento do } \\
\text { parceiro); }\end{array}$ & $\begin{array}{l}\text { - explorador - caça ao parceiro } \\
\text { e as pistas } \\
\text { - articulador - “vender" a } \\
\text { proposta da gamificação } \\
\text { para o parceiro }\end{array}$ \\
\hline $\begin{array}{l}\text { Toque } \\
\text { (aciona o processo de } \\
\text { seleção) }\end{array}$ & $\begin{array}{l}\text { - desvendar os problemas da área, } \\
\text { - desvendar os mistérios (eureka), } \\
\text { - definir o que é relevante; }\end{array}$ & $\begin{array}{l}\text { observador - entendendo } \\
\text { as pistas, desvendando os } \\
\text { mistérios } \\
\text { - selecionador - selecionando } \\
\text { o que é relevante }\end{array}$ \\
\hline $\begin{array}{l}\text { Pouso } \\
\text { (parada - zoom) }\end{array}$ & $\begin{array}{l}\text { - propor caminhos, } \\
\text { - construir a gamificação; }\end{array}$ & $\begin{array}{l}\text { - tecelão (tecendo as pistas), } \\
\text { - colaborador (discutindo e } \\
\text { construindo junto) } \\
\text { - ator (desenvolvendo a } \\
\text { autoria criativa - construção } \\
\text { da gamificação) }\end{array}$ \\
\hline
\end{tabular}




\begin{tabular}{|l|l|l|}
\hline \multicolumn{1}{|c|}{ Missão } & \multicolumn{1}{c|}{ Objetivos } & \multicolumn{1}{c|}{ Achievements } \\
\hline $\begin{array}{l}\text { Reconhecimento } \\
\text { Atento }\end{array}$ & $\begin{array}{l}\text { - construir o mapa da gamificação, } \\
\text { convencer a comunidade de que } \\
\text { o projeto é relevante, } \\
\text { divulgar e conseguir mais } \\
\text { adeptos para a causa. }\end{array}$ & $\begin{array}{l}\text { o cartógrafo (mapeando o } \\
\text { caminho e construindo o } \\
\text { mapa da gamificação). }\end{array}$ \\
\hline
\end{tabular}

Segundo Schlemmer, Chagas e Shuster (2015) a avaliação se deu no acompanhamento dos diferentes percursos de aprendizagem (a partir dos achievements, acima referidos, entendidos como skills para a própria jogabilidade e sociabilidade), trilhados pelos sujeitos ao se engajar e desenvolver o game ou processo gamificado, na forma de projetos de aprendizagem (Schlemmer \& Trein, 2009), os quais possibilitaram conquistar poderes (conhecimentos). A conquista de mais poderes ocorreu na medida em que os sujeitos: ampliavam os observáveis na construção da experiência (em função da atribuição de sentidos à teoria em estudo, na relação com o processo de aprendizagem que estavam experiênciando e a vivência no cotidiano da escola); buscavam e indicavam referências relevantes (textos, áudios, vídeos, jogos, aplicativos, etc.); evidenciavam condutas de autonomia e autoria nos processos de interação e construção do projeto; criavam redes de interações no grupo e entre os grupos; propunham questões, socializavam reflexões e realizavam críticas; compartilhavam os conhecimentos, colaboravam e cooperavam entre si; identificavam o interesse e envolvimento dos estudantes e da comunidade escolar com o game ou situação gamificada criada.

Outro elemento definido foi o projeto que poderia envolver o desenvolvimento de qualquer jogo ou ainda situação gamificada, podendo ser de natureza analógica, digital ou ainda híbrida.

\section{Hibridismo, multimodalidade e pervasividade}

O híbrido é compreendido a partir de Latour (1994) enquanto constituído por múltiplas matrizes, misturas de natureza e cultura, portanto, a não separação entre cultura/natureza, humano/não humano, etc. No contexto deste artigo, tratase de ações e interações entre atores humanos e não humanos, em espaços de natureza analógica e digital, em um imbricamento de diferentes culturas (digitais e pré-digitais), constituindo-se em fenômenos indissociáveis, redes que interligam naturezas, técnicas e culturas. Dessa forma, para Latour (1994), os híbridos emergem como intermediários entre elementos heterogêneos - objetivos e subjetivos, individuais e coletivos. São formas que "se conectam ao mesmo tempo à natureza das coisas e ao contexto social, sem, contudo, reduzir-se nem a uma coisa nem a outra" (Latour, 1994, p.11). Essa intermediação é possível, segundo o autor, pois tais elementos não são estanques. Portanto, o híbrido é aqui compreendido quanto à 
natureza dos espaços (analógico e digital), quanto à presença (física e digital), quanto às tecnologias (analógicas e digitais) e quanto à cultura (pré-digital e digital).

No que se refere ao multimodal, entendem-se distintas modalidades educacionais imbricadas, ou seja, modalidade presencial-física e modalidade online, podendo combinar eletronic learning (e-learning), mobile learning (m-learning), pervasive learning (p-learning), ubiquitous learning (u-learning), immersive learning (i-learning), gamification learning (g-learning) e game based learning (GBL).

Para Saccol, Schlemmer e Barbosa (2011), ubiquitous learning (aprendizagem ubíqua) se refere a processos de aprendizagem que podem ocorrer com o uso de dispositivos móveis, conectados a redes de comunicação sem fio, sensores e mecanismos de geolocalização, capazes de colaborar para integrar os aprendizes a contextos de aprendizagem e a seu entorno, permitindo formar redes presenciais físicas e digitais virtuais entre pessoas, objetos, situações ou eventos. O conceito ubiquitous learning, para além da mobilidade, indica que as tecnologias digitais potencializam a aprendizagem situada, disponibilizando ao sujeito uma gama de informações "sensíveis" ao seu perfil, suas necessidades, seu ambiente e a demais elementos que compõe seu contexto de aprendizagem em qualquer lugar e a qualquer momento. A essa possibilidade podem estar vinculadas tecnologias de localização (GPS, sistemas de navegação, sistemas de localização de pessoas, jogos móveis); tecnologias de identificação (RFID e QR Code); sensores, entre outras.

Relacionada à mobilidade e à ubiquidade estão também a RM e a RA, as quais combinam uma cena presencial física, vista por um sujeito, com uma cena digital virtual, sendo que, no caso da RA, o digital acrescenta informação à cena presencial física ampliando-a, ou seja, "aumenta a cena", potencializando o conhecimento a respeito de objetos, lugares ou eventos. Tanto a RM quanto a RA possuem conceitos diferentes e diversos tipos de configurações, porém ambas consistem, basicamente, no reconhecimento de um objeto, nomeado "marcador", projetado em um ambiente presencial físico, uma câmera que captar esse objeto e um software específico, capaz de receber as informações enviadas pela câmera, interpretá-las e projetar a informação digital virtual sobre o objeto do espaço presencial físico.

Desse modo, é importante considerar que o hibridismo e a multimodalidade comportam diferentes formas de presença, oportunizando, inclusive, presença simultânea em espaços distintos, por exemplo, quando um sujeito está presente, de forma presencial física, em um ambiente educacional no mundo presencial físico (biblioteca, sala de aula, auditório, entre outros), agindo e interagindo com diferentes atores humanos e não humanos que também estão fisicamente presentes nesse espaço, e, simultaneamente, está presente de forma digital virtual, por meio de um avatar, em um mundo digital virtual em $3 \mathrm{D}$, ou ainda por meio de um personagem em um game on-line, agindo e interagindo com outros atores também humanos e não humanos que, assim como ele, estão presentes de forma digital virtual. É preciso considerar ainda a presença digital virtual por meio de um perfil nas mídias sociais ou ainda a telepresença por meio de videoconferência e webconferência. 
Lembrando que, ao falar de mobilidade, pervasividade, ubiquidade, de certa forma, já estamos falando do híbrido e do multimodal, pois, são perspectivas que hibridizam a natureza dos espaços (analógico e digital), a presença (física e digital), as tecnologias (analógicas e digitais). Ainda quanto à gamificação e à aprendizagem baseada em jogos, essas podem ou não envolver contextos de hibridismo e multimodalidade, dependendo de como são desenvolvidas. Porém, o hibridismo e a multimodalidade, ao apresentar múltiplas possibilidades de inscrição e participação, introduz um campo problemático no que diz respeito ao acompanhamento e avaliação das aprendizagens. A pulverização dos espaços de participação e registro podem gerar dificuldades tanto para professores quanto para os estudantes. A gamificação, apesar de criar condições que, de certa forma, organizam ou distribuem esses espaços de ação e participação de forma coordenada e intencional, por si só, pode não ser suficiente para que seja possível acompanhar processos que, dependendo da abertura do campo de possibilidades de um jogo, são imprevisíveis. É em função dessa constatação que buscamos no método cartográfico de pesquisa-intervenção, elemento inspiradores, que associados a perspectiva dos games, da gamificação e da metodologia de projetos de aprendizagem, nos possibilite a construção de novas práticas pedagógicas que nos permitam acompanhar os diferentes percursos de aprendizagem, intervindo, quando necessário.

\section{DESIGN METODOLÓGICO DA PESQUISA}

A pesquisa é de natureza exploratória e descritiva, abordagem qualitativa, inspirada no método cartográfico de pesquisa-intervenção (Kastrup 2007, 2008; Passos, Kastrup e Escóssia, 2009) e, faz uso da observação participante, diário de bordo e registros em forma de texto, audio, fotografia e vídeo digitais deixados na forma de rastros em diferentes espaços de interação.

No contexto das pesquisas que desenvolvemos no GPe-dU UNISINOS/CNPq temos explorado metodologias de pesquisa e intervenção que possam inspirar novas práticas que estejam alinhadas a necessidade de compreender o fenômeno das aprendizagens na sua complexidade. Assim, o método cartográfico de pesquisa e intervenção passou a ser objeto de estudo. Segundo Kastrup (2007), a cartografia é um método que visa acompanhar um processo, e não representar um objeto. Em linhas gerais, trata-se sempre de investigar um processo de produção, sem buscar estabelecer um caminho linear para atingir um fim. "A cartografia procura assegurar o rigor do método sem abrir mão da imprevisibilidade do processo de produção do conhecimento, que constitui uma exigência positiva do processo de investigação ad hoc" (ibidem, p. 19). Sua construção caso a caso, não impede que se procure estabelecer algumas pistas que têm em vista descrever, discutir e, sobretudo, coletivizar a experiência do cartógrafo. A atenção cartográfica é definida como concentrada e aberta, caracterizando-se por quatro variedades: o rastreio, o toque, o pouso e o reconhecimento atento. Por se tratar de pesquisa-intervenção, a análise 
se dá no processo, ou seja, no movimento da cartografia, o que possibilita realizar a intervenção. Os dados produzidos na cartografia foram organizados, categorizados e armazenados em base de dados dinâmicos, utilizando o NVivo. A interpretação dos dados foi realizada a partir do referencial teórico que fundamenta a pesquisa.

\section{RESULTADOS, CONSIDERAÇÕES FINAIS E DISCUSSÕES}

Retomo o problema e objetivo, a fim de apresentar alguns dos resultados obtidos, realizar as considerações finais e as discussões.

Com relação ao problema que consistiu em investigar como os games e a gamificação podem contribuir para a criação de novos desenhos na EaD que sejam significativos para os sujeitos do ponto de vista da aprendizagem, os resultados apontam que:

- Os Games e a Gamificação possibilitaram o desenvolvimento de situações de ensino e de aprendizagem, que se configuraram enquanto Espaço de Convivência Híbrido, Multimodal e Pervasivo, construído num processo de co-criação, a partir da leitura critíca do cotidiano das escolas, as quais as estudantes da Pedagogia estavam vinculadas, o que lhes permitiu identificar problemáticas, em que os games e gamificação poderiam contribuir como possibilidade para mudanças.

- A vinculação da prática pedagógica no contexto da AA-EAMD, com a leitura do cotidiano das escolas, possibilitou um estranhamento e uma análise crítica da realizade, a partir do estabelecimento de relações com as teorias em estudo.

- A vivência dessa prática na vinculação com o percurso de aprendizagem, trilhado por cada Clã no desenvolvimento do game ou processo gamificado na escola, resultou em maior engajamento das estudantes na AA-EAMD; na ampliação da significação sobre a aprendizagem que ocorreu, a partir dessa vivência e; na ressignificação da experiência vivenciada na formação inicial para o ensino fundamental, possibilitando as estudantes atribuir sentido a docência na contemporaneidade.

- Participar de um game ou processo gamificado e simultaneamente, realizar um game ou processo gamificado na escola, possibilitou as estudantes da AAEAMD um sentimento profundo de confiança e de autoestima, o que contribuiu para que a aprendizagem fluisse. Assim, ao conseguir identificar problemas na observação do cotidiano das escolas e contribuir para a sua solução, as estudantes experimentam um sentimento positivo de realização e competência, e isso ajudou a se motivarem ainda mais para o próximo desafio.

- A organização por clãs, aliada ao desafio proposto na narrativa que envolveu realizar missões, instigou a prática colaborativa e cooperativa, pois, necessitaram definir estratégias e se organizar para desenvolver o game e/ou processo gamificado. 
Outros resultados se referem ao próprio processo do desenvolvimento da pesquisa, o que resultou:

- No aprofundamento teórico sobre a tecnologia-conceito Espaços de Convivência Híbridos, Multimodais e Pervasivos, bem como a ampliação da compreensão da contribuição dos Games e do conceito de Gamificação enquanto estratégia de aprendizagem.

- Na articulação entre a pesquisa, a educação superior (Licenciatura em Pedagogia - AA-EAMD) e a educação básica (escolas nas quais as estudantes da AA-EAMD atuavam).

A partir desses resultados, é possível compreender que os games se tornam significativos para os jogadores, principalmente, porque possibilitam viver uma experiência na qual são desafiados a explorar, a realizar missões, o que os coloca no controle do processo, possibilitando assim, por meio de suas ações e interações constantes, descobrir e inventar caminhos e soluções, tomando decisões. Tudo isso de forma divertida, favorecendo a imersão (estado de flow), agência e transformação, propiciando maior engajamento.

Essa proposta, inspirada pelo método cartográfico de pesquisa, enquanto prática pedagógica intervencionista em processos gamificados e games e, desenvolvida em um contexto híbrido, multimodal e pervasivo - propicia acompanhar os sujeitos em seus diferentes percursos de aprendizagem, envolvendo tecnologias analógicas e digitais, modalidade presencial física e on-line, instigando-os a desenvolverem suas próprias missões e projetos que, pela perspectiva do BYOD, podem se prolongar para muito além do tempo definido para a educação formal. $O$ fato de o sujeito possuir um dispositivo móvel e estar conectado, cria condições para que ele continue engajado no processo, independentemente do tempo e do espaço. Sendo assim, o processo de acompanhamento e avaliação pode, em diferentes momentos, estar "situado" e ainda imbricado. Através das pistas, desenhadas e planejadas de forma a proporcionar a hibridização dos espaços analógicos e digitais, foi possível estabeler um contexto multimodal, o que é desejável quando se fala em imersão, agenciamento e engajamento.

A efetivação de um espaço de convivência híbrido, multimodal e pervasivo ocorreu a partir: 1) da integração de diferentes tecnologias analógicas e digitais, que favoreceram diferentes formas de comunicação e em uma perspectiva multimodal (modalidade presencial física combinada com modalidade on-line, incluindo mobile learning, ubiquitous learning e gamification learning); 2) do fluxo de comunicação e interação entre os sujeitos presentes nesse espaço híbrido e multimodal e; 3) do fluxo de interação entre os sujeitos e os diferentes meios, ou seja, o próprio espaço híbrido e multimodal. A gamificação possibilitou um tipo de interação em que os diferentes sujeitos (estudante e professor) estavam engajados, realizando trocas de informações, compartilhando experiências em um processo de aprender fazendo. 
Esse fazer é fundamental para que o sujeito atribua sentidos, aprenda, justamente por ele estar vivenciando uma experiência, "estar na situação", o que lhe propicia poder falar "de dentro", a partir de seu próprio processo de aprendizagem.

Desse modo, ao falar "de dentro", do que está sendo vivenciado, experienciado, o sujeito vai se tornando parte desse híbrido, atribuindo sentidos, significando, produzindo movimentos, como um dos atores humanos que vai se associando a outros atores humanos e não humanos, na constituição de diferentes redes que vão sendo tecidas na perspectiva multimodal.

Mais especificamente no que se refere aos movimentos propostos por Kastrup (2007; 2008) para o método cartográfico, o desenvolvimento dessa experiência de gamificação permitiu que avaliássemos a potência do método e as inadequações que percebemos na nossa própria experiência de gamificar. A questão que nos pareceu mais desafiadora foi a de garantir a imprevisibilidade e abertura rizomática próprias do método e da atenção cartográfica. Nesse caso, nos parece importante considerar que é preciso investir cada vez mais em mecânicas e dinâmicas que fortaleçam e valorizem as narrativas dos jogadores (como no caso dos RPG).

A discussão surge sobre a necessidade de reconfiguração das práticas pedagógicas e currículos, e a forma de organizá-lo no tempo e no espaço, apartir de problemáticas cotidianas, possibilitando a construção de percursos de aprendizagens, de forma a contribuir para uma educação emancipatória e cidadã.

Assim, é possível dizer que a pesquisa atingiu o objetivo proposto, que foi de compreender a contribuição dos games e da gamificação, pensados a partir do movimento "Games for Change", na perspectiva da configuração de Espaços de Convivência Híbridos, Multimodais e Pervasivos, para a construção de práticas pedagógicas que possibilitem novos desenhos em educação, capazes de engajar os sujeitos na aprendizagem, num movimento de aproximação entre a formação inicial e a educação básica.

\section{REFERÊNCIAS BIBLIOGRÁFICAS}

Chou, Y. (2015). Octalysis: Complete Gamification Framework. Site. Recuperado de www.yukaichou.com

Domínguez, A., Saenz-De-Navarrete, J., De-Marcos, L., Fernández-Sanz, L., Pagés, C., e Martínez-Herráiz, J. (2013). Gamifying learning experiences: practical implications and outcomes. Computers \& Education, 63(1), 380-392.

Fardo, M. L. (2013). A gamificação aplicada em ambientes de aprendizagem: Novas Tecnologias na Educação. Cinted/UFRGS, 11(1), 1-9.
Kapp, K. (2012). The gamification of learning and instruction: game-based methods and strategies for training and education. San Francisco: Pfeiffer.

Kastrup, V. (2007). O funcionamento da atenção no trabalho do cartógrafo. Psicologia \& Sociedade, 19(1), 1522. doi: http://www.scielo.br/scielo. php?script=sci pdf\&pid=So102 71822007000100003\&lng=pt\&nrm=iso\& thng=pt

Kastrup, V. (2008). O método cartográfico e os quatro níveis da pesquisa-intervenção. 
Em L.R. Castro e V. Besset, (Orgs.), Pesquisa-intervenção na infância $e$ adolescência. (465-489). Rio de Janeiro: Nau editora.

Latour, B. (1994). Jamais fomos modernos. São Paulo: Editora 34.

Maturana, H. R., e Varela, F. J. (2002). A árvore do conhecimento: as bases biológicas da compreensão humana. São Paulo: Palas Athena.

Maturana, H., e Yãnèz, X. (2009). O Habitar Humano. São Paulo: Palas Athenas.

McGonigal, J. (2011). Reality is broken: why games make us better and how they can change the world. New York: Penguin Press.

Passos, E., Kastrup, V., e Escóssia, L. (2009). Pistas do método da cartografia: pesquisa-intervenção e produção de subjetividades. Porto Alegre: Sulina.

Saccol, A. Z., Schlemmer, E., e Barbosa, J. L. V. (2011). M-learning e u-learning: novas perspectivas da aprendizagem móvel $e$ ubíqua. São Paulo: Pearson Education.

Schlemmer, E. (2014). Gamificação em espaços de convivência híbridos e multimodais: design e cognição em discussão. Revista Faeeba - Educação e Contemporaneidade, 23(42), 73-89.

Schlemmer, E. (2016). Hibridismo, multimodalidade e nomadismo: codeterminação e coexistência para uma educação em contexto de ubiquidade.
En D. R. S. Mill e N. M. Pimentel (Org.), Qualidade na educação: convergências de sujeitos, conhecimentos, práticas e tecnologias. São Carlos: EDUFCar. (no prelo)

Schlemmer, E., e Trein, D. (2009). Projetos de aprendizagem baseados em problema no contexto da web 2.0: possibilidades para a prática pedagógica. Revista e-Curriculum, 4(2), 1-20.

Schlemmer, E., Chagas, W. S., e Schuster, B. E. (2015). Games e Gamificação na Modalidade EaD: da prática pedagógica na formação inicial em pedagogia à prática pedagógica no ensino fundamental. En IV Seminário Web Currículo e XII Encontro de Pesquisadores em Currículo: Contextos, Aprendizagem e Conhecimento. Pontifícia Universidade Católica de São Paulo (PUCSP). São Paulo: Anais de evento.

Schlemmer, E., e Backes, L. (2015). Learning in Metaverses: Co-Existing in Real Virtuality. Hershey, PA: IGI Global.

Zichermann, G., e Linder, J. (2010). Gamebased marketing. Site. doi: http:/ pt.slideshare.net/nich marketing/gamebased-marketing

Zichermann, G., e Cunningham, C. (2011). Gamification by design: implementing game mechanics in web and mobile apps. Canada: O'ReillyMedia.

\section{PERFIL ACADÊMICO E PROFISSIONAL DO AUTOR}

Eliane Schlemmer. Bolsista Produtividade em Pesquisa do CNPq. Doutora em Informática na Educação e Mestre em Psicologia pela UFRGS. Bacharel em Informática pela UNISINOS. É professora-pesquisadora titular do Programa de PósGraduação em Educação. É líder do Grupo de Pesquisa Educação Digital - GPe-dU UNISINOS/CNPq. É conceptora e desenvolvedora de softwares e ambientes digitais virtuais educacionais. Consultora na área de Educação Digital, Educação Online e Educação Corporativa.

E-mail:elianes@unisinos.br/ elianeschlemmer@gmail.com 


\section{ENDEREÇO DO AUTOR}

Programa de Pós-Graduação em Educação - Escola de Humanidades Universidade do Vale do Rio dos Sinos - UNISINOS

Av. Unisinos, 950 Bairro Cristo Rei São Leopoldo/RS (Brasil)

Fecha de recepción del artículo: 12/09/2015

Fecha de aceptación del artículo: 03/01/2016

\section{Como citar este artigo:}

Schlemmer, E. (2016). Games e Gamificação: uma alternativa aos modelos de EaD. RIED. Revista Iberoamericana de Educación a Distancia, 19(2), pp. 107-124. doi: http://dx.doi.org/10.5944/ried.19.2.15731 